\title{
Advances in Genetic Diagnosis of Autism Spectrum Disorders
}

\author{
Jun Shen • David T. Miller
}

Published online: 14 March 2014

(c) Springer Science + Business Media New York 2014

\begin{abstract}
Autism spectrum disorders (ASD) are a heterogeneous group of neurodevelopmental abnormalities characterized by stereotypical communicative and social impairments, affecting 1 in 88 children in the United States. Both genetic and environmental factors contribute to the etiology of ASD. Autistic traits may be part of features associated with certain syndromes or the sole clinical presentation. Due to extreme heterogeneity and variable expressivity of the condition, clinical diagnosis and management have been challenging. Major advances in genomic technologies, computing power, and bioinformatics analyses have resulted in the accelerated discovery of novel genes and risk loci associated with both inherited and sporadic forms of ASD. Pathogenic genetic defects related to ASD range from single nucleotide variation to gross chromosomal abnormalities. In this review, we first summarize the current understanding of the genetic etiology of ASD; we then discuss how genetic diagnostics may influence the management and genetic counseling of ASD; and finally, we outline the strategy to integrate genetic tests into clinical care of children with ASD. We hope to inform primary care pediatricians and clinical genetic specialists how recent advances in the genetic research of ASD have been translated into clinical genetic testing for patients.
\end{abstract}

\section{J. Shen}

Department of Pathology, Harvard Medical School, Brigham and Women's Hospital, 77 Ave. Louis Pasteur, NRB 160, Boston, MA 02115, USA

e-mail: jshen5@partners.org

\section{T. Miller $(\bowtie)$}

Division of Genetics and Department of Laboratory Medicine, Boston Children's Hospital, 300 Longwood Ave., Hunnewell 5, Boston, MA 02115, USA

e-mail: david.miller2@childrens.harvard.edu
Keywords Autism spectrum disorders (ASD) . Chromosomal microarray (CMA) - Clinical diagnosis . Copy number variation $(\mathrm{CNV}) \cdot$ De novo mutation · Exome sequencing $\cdot$ Genetic testing

\section{Introduction}

Clinical and Epidemiological Features of ASD

Autism spectrum disorders (ASDs) are a heterogeneous group of complex neurodevelopmental conditions characterized by difficulties with social interactions, deficits in verbal and nonverbal communication, and repetitive or stereotypical behaviors. ASDs have traditionally included autistic disorder, childhood disintegrative disorder, pervasive developmental disorder-not otherwise specified (PDDNOS) and Asperger syndrome. Since the May 2013 publication of the new DSM-5 diagnostic manual, these autism subtypes have been merged into one umbrella diagnosis of ASD [1・•].

The estimated prevalence of ASD was about 1 in 88 children in 2008 according to the Autism and Developmental Disabilities Monitoring Network of the Centers for Disease Control and Prevention [2]. Due to this high prevalence, published literature on ASD has undergone rapid growth in recent years (Fig. 1). The prevalence of ASD itself appears also to have increased since 2002, and several factors may explain this trend. First, the diagnostic criteria of ASD include a heterogeneous group of patients, some with higher functioning ASD that may have been previously left out of prevalence estimates. Second, increased awareness and access to services have brought more cases to medical attention, likely including increased numbers of ethnic minorities which were previously not 


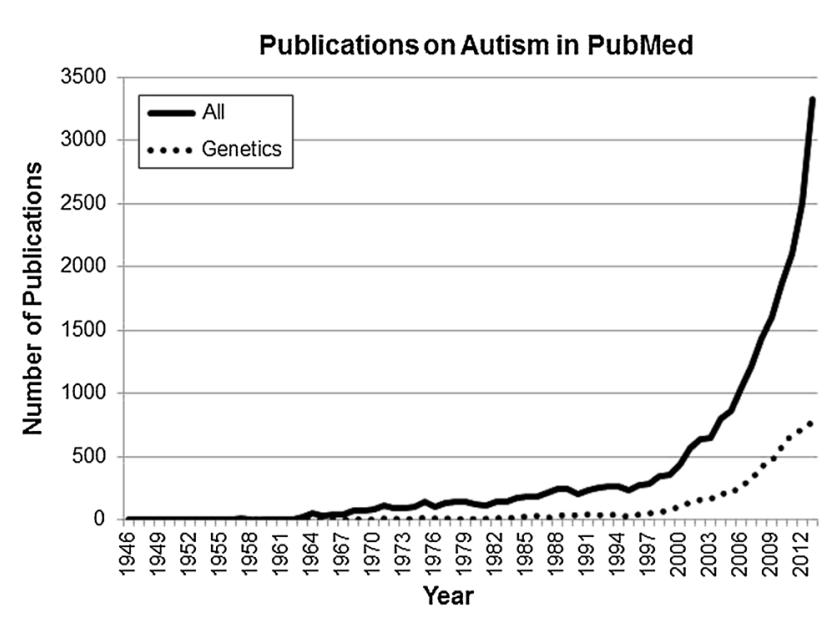

Fig. 1 Publications on autism in PubMed. The number of publications on autism has grown exponentially over the years, and the proportion of articles on the genetics of autism has increased even more rapidly. This trend highlights the importance of genetic diagnosis of ASD and the potential impact on patient care

included. Third, improved screening and diagnostic tools, including genetic testing to identify susceptibility to ASD, have facilitated better ascertainment of patients with ASD. Finally, we still cannot rule out the possibility that unidentified non-genetic risk factors may also contribute to the increased prevalence of ASD to some degree. These factors have led to increased parental concerns, visits to primary care pediatricians, and referrals to clinical specialists for evaluations of individuals with ASD in recent years.

\section{Etiology of ASD: Genetic and Other Factors}

Prior studies have shown that ASD is highly heritable, meaning that it has a strong genetic component. Twin studies in several large cohorts of different populations have consistently shown a much higher concordance rate in monozygotic twins than in dizygotic twins, suggesting that genetic factors play a major role in the etiology [3-5]. Affected male to female ratio has been estimated to be about 4-10 to 1 [6]. Although not completely understood, this gender bias may be due in part to a disproportionate number of genes implicated in ASD lying on the X chromosome. Recent data have shown that siblings of affected female probands had more significant autistic impairments than those of male probands [7]. This observation is consistent with the polygenic threshold model, known as the Carter effect [8]. A certain amount of genetic "burden" is necessary for clinical signs of ASD to manifest. Fewer females manifest ASD because they have a higher threshold. Affected girls may imply a higher familial genetic predisposition.
Determining the cause of ASD in each patient can be challenging for several reasons. Although some ASD cases are attributable to a single genetic locus, multifactorial etiologies are more common, making it difficult to pinpoint the exact cause in many cases. The aforementioned Carter effect also supports a polygenic inheritance model of ASD in many cases. In addition, epigenetic and environmental factors also influence the disease manifestation, since the concordance rate is only $\sim 70 \%$ in male monozygotic twins and even lower in females due to random X-inactivation [9]. The concordance rate for dizygotic twins is higher than that for non-twin siblings and negatively correlates with the age difference, suggesting environmental contribution to the etiology of ASD [10]. Furthermore, many epidemiologic studies have attempted to establish the association of various environmental factors with ASD, such as maternal health conditions, nutrition during pregnancy and breastfeeding, food preference and dietary intake, immunization, video game access, parental rules, teaching strategies, immigration status, and many others [11-16]. However, genetic factors may influence the susceptibility to environmental factors. Therefore, it is still an area of intensive research to determine how the genetic and environmental factors interact to result in the ASD phenotype.

\section{Current Understanding of the Genetic Etiologies of ASD}

Specific Genetic Syndromes Associated with ASD

The genetic causes of ASD are extremely heterogeneous. Many genes have been implicated in ASD and the number continues to grow. ASD may present as features in recognized single gene disorders or clinically well-defined syndromes such as Angelman syndrome [17], CHARGE syndrome [18], Cohen syndrome [19], Cornelia de Lange syndrome [20], Duchenne/Becker muscular dystrophy [21, 22], fragile $X$ syndrome [23, 24], neurofibromatosis type 1 [25], Prader-Willi syndrome [26•], PTEN-related syndromes [27, 28•], Rett syndrome [29], Smith-Magenis syndrome [30], Sotos syndrome [31], and tuberous sclerosis complex (TSC) [32]. ASD also occurs at a higher rate among children with certain inborn errors of metabolism such as adenylosuccinase deficiency [33], branched-chain ketoacid dehydrogenase kinase deficiency [34•], epsilontrimethyllysine hydroxylase deficiency [35], phenylketonuria (PKU) [36], Sanfilippo syndrome [37], and SmithLemli-Opitz syndrome [38]. Because these specific syndromes are very rare and all patients do not invariably manifest autistic traits, each syndrome only contributes to a very small percentage to the etiology of ASD. However, 
collectively they may account for approximately $5 \%$ of the described genetic causes of ASD [39].

\section{Chromosomal Aberrations}

Chromosomal aberrations include aneuploidy (abnormal chromosome copy number) and structural variation such as deletions, duplications, inversions, and translocations. The most recognizable example of whole chromosome aneuploidy is trisomy 21 or Down syndrome, but segmental aneuploidy (extra or missing copies of a shorter chromosome segment) are an even more common cause of ASD, as discussed below. These abnormalities are found at higher frequencies among ASD patients, and ASD prevalence is also higher in patients with chromosomal abnormalities than in the general population [40]. Recent studies have reported ASD in $19 \%$ of patients with Down syndrome [41] or with sex chromosome aneuploidies [42], and even more common in segmental aneuploidies (microdeletion or microduplication) of chromosomes 2q37 [43], 15q11-13 [44], and 16p11.2 [45].

Prior to the development of molecular probes for chromosome regions such as fluorescence in situ hybridization (FISH), the only chromosomal changes observed were those large enough to be seen through conventional G-banded karyotyping and light microscopy. Within the last 10 years, an even more powerful technology to examine chromosomes at much higher "magnification" has been widely adopted. Through this technique of chromosomal microarray (CMA), numerous submicroscopic copy number variations (CNVs) throughout the genome have been identified in individuals with ASD [46]. Numerous studies have consistently demonstrated a diagnostic yield of at least $7 \%$ with CMA in pediatric and adult cohorts with ASD, much higher than conventional cytogenetic approaches such as karyotype and FISH [47-54]. This higher yield forms the basis for recommending CMA as the first-tier genetic diagnostic test for non-specific cases of ASD [48, 55••].

The widespread use of CMA has revealed many rare CNVs that are unique to each patient as well as recurrent microdeletion/microduplication syndromes associated with ASD [56-59]. Chromosome microdeletion/microduplication can also lead to significant co-morbidities including developmental delay, intellectual disability, dysmorphic features, congenital anomalies, epilepsy, schizophrenia, and other neuropsychiatric diagnoses. Some CNVs are inherited from a parent whose clinical presentation may vary, a phenomenon known as variable expressivity. In other cases, pathogenic CNVs arise as a new (de novo) change not present in either parent [60, 61]. Clinical interpretation is based on phenotypic presentations, the $\mathrm{CNV}$ size, the gene content within the CNV region, de novo status, and the relative frequencies of similar CNVs in available databases of ASD cases and of general population controls. The clinical significance of many CNVs may remain uncertain until more data become available.

\section{Indications for Clinical Genetic Testing for ASD}

\author{
Identifying an Etiology for ASD and Guiding Medical \\ Management
}

The goals of clinical genetic testing are to determine a specific etiology, which may facilitate decisions about clinical management, and to provide more accurate estimates of recurrence risk for future pregnancies in the same family. Examples of impact on clinical management include identification of other medical issues that may be associated with the genetic cause and may benefit from specialty referral, surveillance for other potential medical complications, or further diagnostic testing for a related medical issue [62•]. Furthermore, genetic testing has the potential to identify individuals with a genetic susceptibility to ASD regardless of clinical symptoms. Identifying children with ASD at an early age is important because it has been well recognized that timely early intervention can improve the development of children with ASD, and help them to acquire social function and self-help skills [63-66]. With the discovery of many genes associated with ASD, there are many considerations for ordering the appropriate genetic test and providing appropriate counseling to the family before and after testing [55••].

\section{Refining Recurrence Risks Within a Family}

A definitive genetic diagnosis may refine recurrence risks. Without genetic testing, recurrence risks are determined empirically based on population data. Estimates of recurrence risk vary. The 2013 American College of Medical Genetics and Genomics (ACMG) revised practice guideline relies on established data to suggest a recurrence risk of $7 \%$ if the proband is female and $4 \%$ if the proband is male [55••]. If multiple children (two or more) are affected, recurrence risk increases to about $33 \%$ or more. Newer data suggest a recurrence risk of $7-19 \%$ when one child is affected, and similar risk of $33 \%$ or more when two or more children in a family are affected [67-69]. The ACMG guideline suggests using the lower risk estimates until the newer results have been replicated.

Because of the high degree of heterogeneity of the etiology and wide spectrum of clinical presentations, the risk estimate is often within a wide range that is not particularly helpful to each family. Recent advances in the identification of ASD-associated genomic variants and the 
availability of sensitive high-throughput genetic testing approaches have enabled accurate identification of genetic causes of ASD and individualized precise estimation of the recurrent risks for family members. Identification of a de novo causative variant indicates a recurrence risk of $\sim 1 \%$, much lower than the population average. This $1 \%$ risk is due to the possibility of germ-line mosaicism in the parents. In contrast, identification of a disease-causing variant inherited from an affected parent would suggest a recurrence risk as high as $50 \%$ in future children.

Even in cases where a specific genetic cause of ASD has been identified, counseling about recurrence risk may not be straightforward. Genetic variants may manifest differently among members of the same family depending on the mode of inheritance, penetrance, and expressivity of the particular variants. For example, autosomal dominant inheritance, where a defect in only one copy of the gene is sufficient to cause ASD, confers a $50 \%$ recurrent risk (unless de novo). In the case of autosomal recessive inheritance, where both copies of the gene are affected, the recurrent risk is $25 \%$. For $\mathrm{X}$-linked genes, the recurrence risks are different for male and female fetuses. Some conditions, such as maternally inherited duplication of $15 q 11$, can be passed on in a dominant manner from an unaffected parent, because the manifestation of the disease phenotype depends on the parental origin of the variant as a result of genetic "imprinting".

Penetrance describes the proportion of individuals carrying a particular genetic variant who exhibit clinical signs or symptoms of the disorder associated with that gene. When a genetic variant shows incomplete penetrance, some carriers are unaffected. Variable expressivity refers to a situation where all carriers of the genetic variant are affected but with a range of severity for those signs and symptoms, even within the same family. The penetrance of some symptoms is incomplete for many of the genetic variants associated with ASD. For example, chromosome 16 p11.2 deletion is a known susceptibility factor for ASD, but in the largest cohort study only about $15 \%$ of children with 16p11.2 deletion had ASD [70]. If considering neuropsychiatric disorders in aggregate, however, over $80 \%$ of $16 \mathrm{p} 11.2$ deletion carriers had a psychiatric diagnosis such as ASD, attention deficit-hyperactivity disorder (ADHD), anxiety disorders, mood disorders, gross motor delay, and epilepsy [70]. Among the same cohort, all carriers of $16 \mathrm{p} 11.2$ deletion showed lower full-scale intelligence quotient (FSIQ) scores compared to family members without the deletion, indicating full penetrance for an effect on cognitive ability. There was variable expressivity for the trait of cognitive ability, with a wide range of FSIQ among individuals with $16 \mathrm{p} 11.2$ deletion, as reviewed elsewhere [71]. Therefore, a genetic variant present in an apparently unaffected parent does not necessarily imply that the variant is benign.
Identifying a Genetic Susceptibility Prior to Clinical Diagnosis of ASD

Although genetic testing may determine a specific etiology, ASD is by definition a clinical diagnosis based on behavioral criteria. In very young children, it may be difficult to identify symptoms or establish a clinical diagnosis of ASD. At the same time, the family history may indicate an increased concern, such as an older sibling with ASD and a positive genetic test result. Recent large-scale validation of early screening instruments for ASD in children before 2 years old have demonstrated the sensitivity to identify at risk children, but only about half of children who screened positive met the diagnostic criteria, while most of them may benefit from intervention [72]. Therefore, in cases such as a younger sibling with some developmental delays, and where ASD is suspected but patients do not fully meet clinical criteria for ASD, genetic testing for the familial genetic variant may provide a basis for improved surveillance and early intervention.

\section{Approaches to Clinical Genetic Testing for Patients with ASD}

Clinical Evaluation: Medical History, Family History, and Physical Examination

A medical history revealing multiple congenital anomalies should prompt consideration of a referral to a clinical geneticist to evaluate for possible genetic syndromes. Next, a three-generation family history may identify a potential mode of inheritance for ASD within a family. The proband is the first individual in the family brought to medical attention and often has the most striking or severe clinical features. If a parent of the proband also shows some features of ASD, the ASD in the family may be dominantly inherited, especially when there are multiple affected individuals in different generations and branches of the pedigree. If both parents are unaffected, the ASD may be de novo, recessive, dominant with incomplete penetrance, or of complex (multifactorial) inheritance. If the proband is born to non-consanguineous (unrelated) parents and is the only one affected in the extended family, de novo occurrence is more likely. If only siblings in one generation are affected, or if the parents are consanguineous, the etiology is more likely recessive. If multiple biologically related individuals in different generations and branches are affected, the inheritance may be dominant, but could also be complex (multifactorial). If there is father-to-son transmission of the ASD traits in a family, X-linked inheritance may be ruled out. Finally, if the physical examination reveals dysmorphic features, the patient 
Fig. 2 Clinical genetic testing for non-syndromic ASD. Genetic tests are tiered according to ACMG clinical practice guidelines. $A S D$ Autism spectrum disorder, $C M A$ chromosomal microarray analysis, $F H x$ family history, MECP2 methyl CpG binding protein 2 gene, MRI magnetic resonance imaging, PTEN phosphatase and tensin homolog gene, $S D$ standard deviation

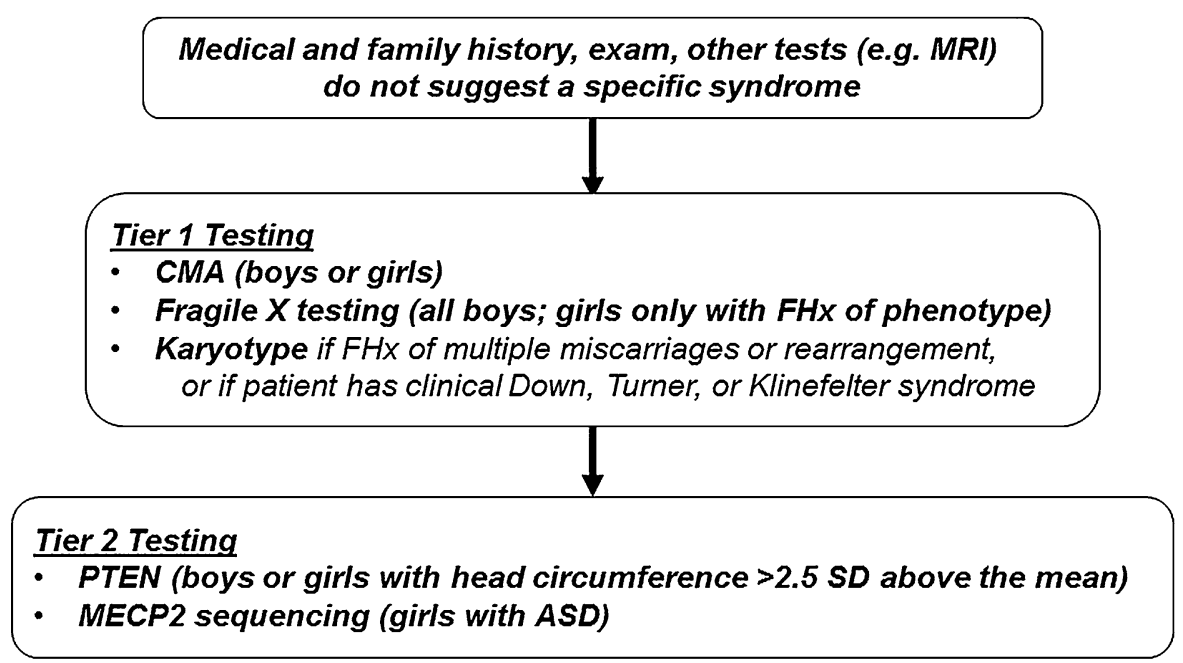

Fig. 3 Comparisons of genetic testing approaches. The horizontal axis shows the increased test complexity as the scope of genetic testing grow from single nucleotide variant to the entire human genome. The vertical axis shows the resolution of different test from low resolution G-banded karyotyping of several megabases to nucleotide level at the highest. Larger circles indicate higher diagnostic yield and lighter circles indicate newer tests

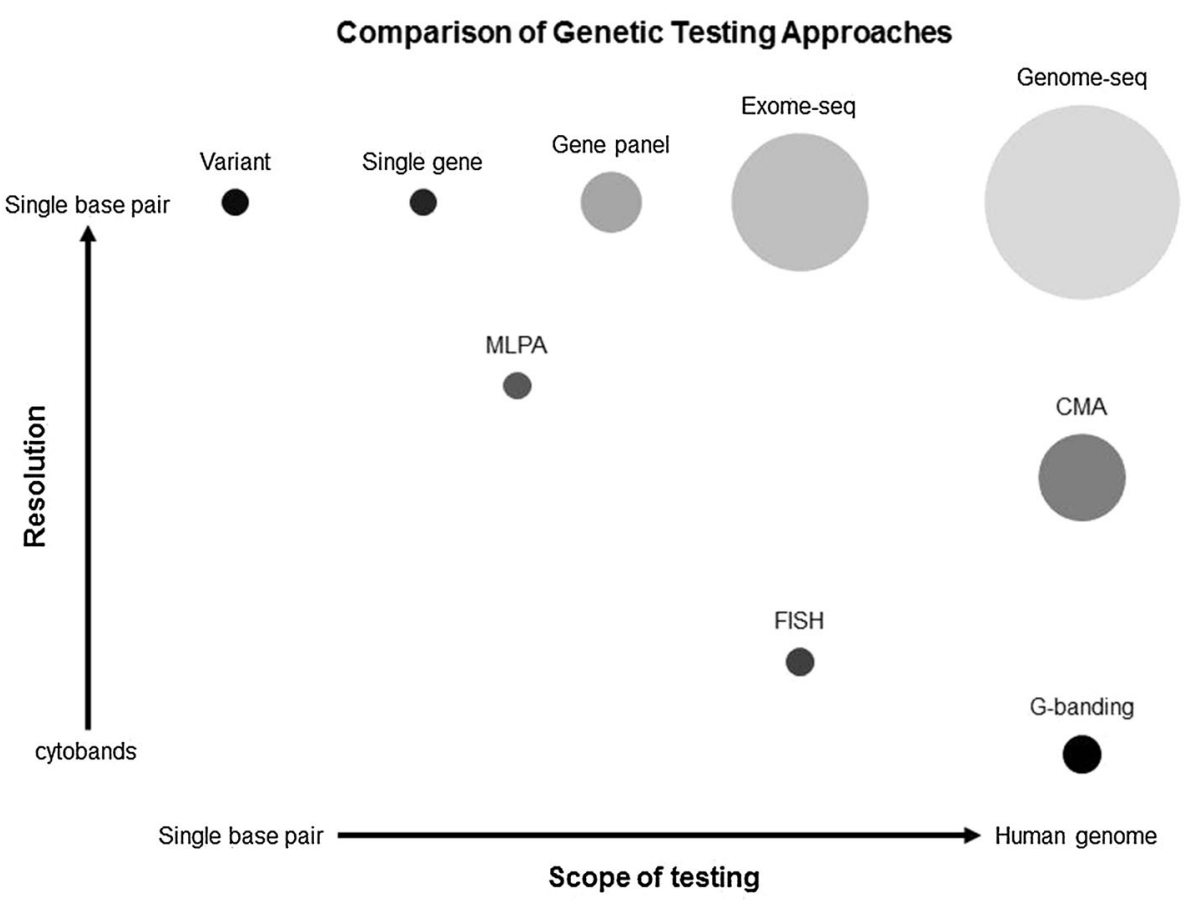

should be referred to a clinical geneticist who may be able to recognize a specific syndromic form ASD such as Rett syndrome, Angelman syndrome, Prader-Willi syndrome, or tuberous-sclerosis complex. Suspicion of such a syndrome would prompt specific genetic testing.

Tier 1 Testing: CMA and Fragile X Testing for Patients with Non-specific Features

Most patients with suspected ASD will not have specific medical issues or dysmorphic features. Genetic testing could be considered for such patients prior to a consultation with a clinical geneticist. A tiered diagnostic strategy is outlined (Fig. 2) to guide a non-geneticist clinician. With its relatively high diagnostic yield of $7 \%$ or greater (Fig. 3; Table 1), CMA has been recommended as a first tier test for these patients [55••]. CMA test results are sometimes difficult to interpret, because it may reveal variants of uncertain significance due to our limited understanding. It may also reveal incidental findings unrelated to ASD. It is therefore important to offer the test only if pre- and post-genetic counseling services are in place.

Approximately $0.5-5 \%$ of non-specific ASD cases are due to fragile $X$ syndrome (Table 1) [47, 55••, 73]. Fragile $\mathrm{X}$ syndrome has long been associated with ASD [23]. 
Table 1 Comparisons of genetic testing approaches to the diagnosis of ASD

\begin{tabular}{|c|c|c|c|}
\hline Type & Purposes & $\begin{array}{l}\text { Approximate } \\
\text { Dx yield }(\%)\end{array}$ & Limitations \\
\hline $\begin{array}{l}\text { Specific } \\
\text { variant }\end{array}$ & $\begin{array}{l}\text { Detect common known variants } \\
\text { Detect specific familial variants } \\
\text { Determine parental origin of variants } \\
\text { Establish de novo status }\end{array}$ & NA & Known specific variants only \\
\hline FISH & $\begin{array}{l}\text { Detect specific chromosomal abnormalities } \\
\text { Confirm CMA findings }\end{array}$ & $<1$ & $\begin{array}{l}\text { Specific chromosomal regions with available FISH } \\
\text { probes only }\end{array}$ \\
\hline $\begin{array}{l}\text { Single gene } \\
\text { sequencing }\end{array}$ & $\begin{array}{l}\text { Detect small nucleotide sequence variants in a } \\
\text { known ASD-associated gene }\end{array}$ & $<1$ & Single gene only. Unable to detect structural variation \\
\hline MLPA & $\begin{array}{l}\text { Detect gains and losses in targeted chromosomal } \\
\text { regions }\end{array}$ & $<1$ & $\begin{array}{l}\text { Gain or losses in targeted chromosomal regions with } \\
\text { available MLPA probes only }\end{array}$ \\
\hline Special tests & DNA methylation, repeat expansion, UPD & $<1$ & $\begin{array}{l}\text { Known syndromes with special types of genetic variants } \\
\text { only }\end{array}$ \\
\hline $\begin{array}{l}\text { ASD gene } \\
\text { panel }\end{array}$ & Variants in a panel of known ASD-associated genes & 5 & Known genes only. Unable to detect structural variation \\
\hline $\begin{array}{l}\text { G-banded } \\
\text { karyotyping }\end{array}$ & $\begin{array}{l}\text { Gross chromosomal abnormalities including } \\
\text { aneuploidy, large deletions, duplications, } \\
\text { insertions, inversions, and translocations. }\end{array}$ & 2 & Low resolution \\
\hline CMA & $\begin{array}{l}\text { Chromosomal gains and losses (CNVs) in the } \\
\text { genome }\end{array}$ & $>7$ & $\begin{array}{l}\text { Unbalanced chromosomal abnormalities only. Medium } \\
\text { Resolution. Unknown location of gains. Variants of } \\
\text { uncertain clinical significance. Incidental findings } \\
\text { irrelevant to ASDs }\end{array}$ \\
\hline $\begin{array}{l}\text { Exome } \\
\text { sequencing }\end{array}$ & $\begin{array}{l}\text { Small DNA sequence variants in the protein coding } \\
\text { and splice site regions in the genome }\end{array}$ & $10-15$ & $\begin{array}{l}\text { Coding region and flanking splice sites only. More } \\
\text { variants of uncertain significance and incidental } \\
\text { findings than CMA }\end{array}$ \\
\hline $\begin{array}{l}\text { Genome } \\
\text { sequencing }\end{array}$ & $\begin{array}{l}\text { DNA sequence and copy number variants in the } \\
\text { genome }\end{array}$ & $>15$ & $\begin{array}{l}\text { More variants of uncertain significance and incidental } \\
\text { findings than exome sequencing }\end{array}$ \\
\hline
\end{tabular}

Types of tests are listed from the most specific to the most comprehensive. In general, a more specific test is less likely to give a positive result, but the results would be more interpretable and informative

$A S D$ Autism spectrum disorder, $C M A$ chromosomal microarray analysis, $C N V$ copy number variation, $D N A$ deoxyribonucleic acid, $d x$ diagnostic, FISH fluorescent in situ hybridization, MLPA multiplex ligation-dependent probe amplification, UPD uniparental disomy

Recent studies suggest that fragile $\mathrm{X}$ mental retardation protein (FMRP) plays a key role in regulating genes involved in neurodevelopment, many of which are ASD genes [74, 75]. Because fragile $\mathrm{X}$ is a short-tandem-repeat expansion disorder that leads to abnormal DNA methylation, neither gene sequencing nor CMA will detect the abnormality. Specialized tests to assay the number of repeats and methylation of the gene region should be considered. The ACMG guideline recommends routine testing of fragile $\mathrm{X}$ in all boys with ASD, and in girls if there are other features of the history to suggest that possibility, such as a history of premature ovarian failure in the mother or individuals in the family with ataxia that may be due to the fragile $\mathrm{X}$ tremor-ataxia syndrome (FXTAS) $[55 \bullet \bullet$.

\section{Tier 2 Testing: Specific Genetic Causes of ASD}

When the aforementioned tests yield positive results, patients and their family members should be referred to a clinical geneticist and/or genetic counselor to understand the genetic counseling implications and potentially to discuss management plans for related medical complications. Even when the test results are negative or inconclusive, additional testing may be indicated. As mentioned, a clinical genetics evaluation should be considered for individuals with ASD and congenital anomalies or dysmorphic features with the goal of identifying a possible etiology for each patient and choosing appropriate testing for the clinical situation. A clinical geneticist is best able to recognize genetic syndromes in order to prioritize the choice of genetic testing to achieve the highest chance of identifying an etiology [64]. A clinical genetic specialist evaluates an individual's medical history, family history, prior laboratory results, and physical examination findings to determine which diagnostic tests have the highest probability to yield useful information. Tests for specific syndromes are considered based on clinical evaluations. These include $P T E N$ testing for boys or girls with ASD and macrocephaly as well as $M E C P 2$ testing for girls with ASD (Fig. 2). 
Additional Testing to be Considered in Consultation with a Clinical Geneticist

If the results of Tier 1 and 2 testing are negative, a clinical geneticist may consider ordering additional genetic testing tailored to the patient's medical history, family history, or unique physical exam features. A comparison of the different types of tests and their purposes and limitations are also given (Fig. 3; Table 1). In some cases, screening for metabolic disorders may be indicated [55••]. In other cases, further molecular testing may be considered. Next-generation sequencing (NGS)-based targeted gene panels and exome sequencing are new high-throughput genetic tests that can detect small DNA sequence changes but not structural variations in general. Several NGS-based gene panels targeting known ASD-associated genes are clinically available. For example, if family history suggests possible X-linked inheritance pattern, an X-linked gene panel may be considered. This strategy restricts the analysis to genes which are rare causes of autism, but the sheer number of genes tested-usually several dozen genesincreases the chance of identifying a variant of uncertain significance. This can complicate the genetic counseling, so tests such as this should be considered only after appropriate pre-test counseling, as mentioned earlier for CMA.

Targeted gene panels detect many more genetic variants than single gene tests, but will not detect variants in novel genes, and diagnostic yield can be biased by the methods used to select genes to be included in the panel. For this reason, exome sequencing targeting all annotated protein coding genes or $\sim 1.5 \%$ of the genome may have an even higher yield than panel testing. Exome sequencing has been used extensively for gene discovery in research settings and demonstrated excellent diagnostic yields (Table 1). Many new ASD-associated genes have recently been identified using this approach [26•, 34•, 76•, 77-81]. However, it is more expensive than targeted sequencing of panels of known ASD genes, and can identify even more variants of uncertain significance in comparison to gene panels. Given the high cost, interpretive challenges, and limited availability of these tests, they are not yet considered standard of care for clinical testing of all patients with ASD, but may be used in some cases at the discretion of a clinical geneticist.

\section{Testing Other Family Members}

Parental testing is often performed to aid the interpretation of variants of uncertain clinical significance. Testing both biological parents of the proband may be informative, although variants inherited from unaffected parents are not necessarily benign. In the case of recessive inheritance, parental samples allow phase determination to confirm whether the two variants occur on the same (in cis) or different (in trans) homologous chromosomes. In the case of de novo variants, absence of the variant in both parents is required to establish the status. In addition, testing other relatives, especially those who are affected, will provide segregation evidence to help determine the clinical significance of the variant and to associate the variant to the phenotypic spectrum of the disorder.

If a causative genetic variant is identified in a proband, the parents may wish to consider testing other family members, including younger siblings. When two or more individuals in a family are affected with ASD, they are likely to share a specific genetic etiology. If a familial variant has already been identified, it is advisable to test for the specific familial variant in additional family members for easier interpretation, less cost, and faster turn-around time. Caution is warranted when performing genetic testing for ASD on siblings or other family members who do not have a clinical diagnosis of ASD. Using genetic test results to predict the likelihood of developing symptoms of ASD is not recommended due to issues of incomplete penetrance and variable expressivity as previously discussed. This is especially challenging in a prenatal setting.

\section{Limitations of Current Genetic Testing Approaches}

Despite rapid discovery of novel ASD associated genes and disease mechanisms in recent years, and tremendous technological improvements in the methodology and throughput of the genetic testing, there are still limitations of genetic testing that prevent it from being a routine screening to identify children with ASD. First, there are inherent technical limitations to the testing methodologies, and each methodology is unable to detect certain types of genetic changes (Table 1). While CMA has been very useful in detecting copy number imbalances in the chromosomes, it cannot detect balanced chromosomal abnormalities (BCAs) or small changes at nucleotide level resolution. Conventional G-banded karyotype may detect BCAs, but studies have shown that microscopically discernable BCAs are observed in $<1 \%$ of ASD patients, and therefore G-banded karyotype is no longer recommended as a routine test for ASD [55••]. Exome sequencing is able to achieve nucleotide resolution but is not robust in detecting CNVs. WGS is capable of detecting both kinds of genetic variations if sequenced at sufficient read-depth $[82 \bullet, 83 \bullet$. However, at the present time, deep WGS is still cost-prohibitive, computationally demanding, accompanied by tremendous interpretation challenges, and is not widely available as a clinical test.

Second, the genotype-phenotype correlations for most genetic variants are not well established, mainly due to the 
complex multifactorial nature of ASD. Although CMA has been recommended by professional authorities to be the first-tier test for children with congenital anomalies, developmental delay, intellectual disabilities, and ASD, the testing laboratory does not necessarily obtain detailed clinical information that would aid the interpretation of particular CNVs in light of specific clinical features.

Finally, standard practices for genetic testing of ASD vary among providers and across regions and countries. Therefore, the types of genetic testing ordered may be inconsistent among different individuals with ASD. The expense of genetic testing and variability in health care coverage may contribute to some of this inconsistency. The out-of-pocket cost to patients and families are difficult to predict, since reimbursement rates vary among different payers. Some areas are still using subtelomeric FISH because certain payers will not approve CMA. Efforts such as the ACMG practice guideline are an attempt to develop a more uniform clinical practice with regard to clinical genetic testing for patients with ASD.

\section{Future Directions}

Genomic research findings are being translated into clinical genetic tests with increased efficiency and diagnostic yield. With the discovery of more ASD genes, the content of custom gene panels will become more comprehensive and will likely improve the diagnostic yield. As the cost of sequencing and computing continues to drop, exome sequencing and eventually WGS will become more widely adopted in clinical use. The roles of noncoding regions of the genome have begun to be understood, and likely play a role in the heritability of ASD. Novel genetic tests that assay transcriptional and epigenetic regulatory consequences of genetic variants will become available and will likely improve the diagnostic yield of genetic testing for ASD even further.

Identification of specific genetic causes of ASD will increase our understanding of the underlying disease mechanisms, so physicians can counsel families with enhanced information. Although currently there is no cure for ASD, exciting discoveries of genes associated with the condition have stimulated investigations into the pathologic mechanisms, and have suggested molecular pathways that could be potential therapeutic targets. Clinical trials are actively underway [84-86]. Because of the heterogeneous etiology of ASD, therapeutic efficacy will likely vary for different individuals. There is hope that knowing the underlying genetic etiology in ASD patients will not only help establish the correlation between the genotype and therapeutic efficacy initially but also direct optimal choice of management plan for personalized medicine in the long run.

\section{Conclusion}

ASD is a complex disorder with a high heritability. Recent progress in the identification of genes associated with the condition and improvement in genetic testing methods have enabled clinicians to apply genetic testing to the care of patients with ASD. Genetic testing offers the opportunity for early identification of increased susceptibility to ASD, determination of a more specific etiology, and refinement of recurrence risks. Continued technological improvements will likely lead to further cost reduction and increased sensitivity of genetic testing for ASD. However, that increased sensitivity also has a cost in the form of identification of variants of uncertain significance. Therefore, interpreting genetic test results will continue to present a challenge despite automation of data generation. Further research is necessary to establish and clarify genotype-phenotype correlations of the genetic variants identified in patients. This will most likely occur through collaborations between physicians and testing laboratories and is crucial to demonstrating the clinical utility of genetic testing for ASD.

Disclosures David T. Miller is a Clinical Consultant and Medical Director for Claritas Genomics (no equity), a majority owned subsidiary of Boston Children's Hospital. Jun Shen declares no conflict of interest.

Human and Animal Rights and Informed Consent This article does not contain any studies with human or animal subjects performed by any of the authors.

\section{References}

Papers of particular interest, published recently, have been highlighted as:

- Of importance

•• Of major importance

1. - American Psychiatric Association DSM-5 Task Force. Diagnostic and statistical manual of mental disorders: DSM-5. 5th ed. Washington, D.C.: American Psychiatric Association; 2013. This publication specified the most current diagnostic criteria for ASD which grouped all the subcategories of autism into a single disorder. Physicians should refer to this while evaluating patients with ASD.

2. Autism and Developmental Disabilities Monitoring Network Surveillance Year 2008 Principal Investigators; Centers for Disease Control and Prevention. Prevalence of autism spectrum disorders-Autism and Developmental Disabilities Monitoring Network, 14 sites, United States, 2008. Morbidity and mortality weekly report Surveillance summaries. 2012;61(3):1-19.

3. Rosenberg RE, Law JK, Yenokyan G, McGready J, Kaufmann WE, Law PA. Characteristics and concordance of autism spectrum disorders among 277 twin pairs. Arch Pediatr Adolesc Med. 2009;163(10):907-14. doi:10.1001/archpediatrics.2009.98. 
4. Nordenbaek C, Jorgensen M, Kyvik KO, Bilenberg N. A Danish population-based twin study on autism spectrum disorders. Eur Child Adolesc Psychiatry. 2013;. doi:10.1007/s00787-013-04195.

5. Kerekes N, Brandstrom S, Lundstrom S, Rastam M, Nilsson T, Anckarsater H. ADHD, autism spectrum disorder, temperament, and character: phenotypical associations and etiology in a Swedish childhood twin study. Compr Psychiatry. 2013;. doi:10. 1016/j.comppsych.2013.05.009.

6. Werling DM, Geschwind DH. Sex differences in autism spectrum disorders. Curr Opin Neurol. 2013;26(2):146-53. doi:10.1097/ WCO.0b013e32835ee548.

7. Robinson EB, Lichtenstein P, Anckarsater H, Happe F, Ronald A. Examining and interpreting the female protective effect against autistic behavior. Proc Natl Acad Sci USA. 2013;110(13): 5258-62. doi:10.1073/pnas.1211070110.

8. Carter $\mathrm{CO}$. The inheritance of congenital pyloric stenosis. $\mathrm{Br}$ Med Bull. 1961;17:251-4

9. Hallmayer J, Cleveland S, Torres A, Phillips J, Cohen B, Torigoe $\mathrm{T}$, et al. Genetic heritability and shared environmental factors among twin pairs with autism. Arch Gen Psychiatry. 2011; 68(11):1095-102. doi:10.1001/archgenpsychiatry.2011.76.

10. Bohm HV, Stewart MG, Healy AM. On the autistic spectrum disorder concordance rates of twins and non-twin siblings. Med Hypotheses. 2013;81(5):789-91. doi:10.1016/j.mehy.2013.08.019.

11. Al-Farsi YM, Al-Sharbati MM, Waly MI, Al-Farsi OA, Al-Shafaee MA, Al-Khaduri MM, et al. Effect of suboptimal breastfeeding on occurrence of autism: a case-control study. Nutrition. 2012;28(7-8):e27-32. doi:10.1016/j.nut.2012.01.007.

12. Magnusson C, Rai D, Goodman A, Lundberg M, Idring S, Svensson A, et al. Migration and autism spectrum disorder: population-based study. Br J Psychiatry. 2012;201:109-15. doi:10.1192/bjp.bp.111.095125.

13. Bilder DA, Bakian AV, Viskochil J, Clark EA, Botts EL, Smith $\mathrm{KR}$, et al. Maternal prenatal weight gain and autism spectrum disorders. Pediatrics. 2013;132(5):e1276-83. doi:10.1542/peds. 2013-1188.

14. Lyall K, Munger KL, O’Reilly EJ, Santangelo SL, Ascherio A. Maternal dietary fat intake in association with autism spectrum disorders. Am J Epidemiol. 2013;178(2):209-20. doi:10.1093/ aje/kws433.

15. Engelhardt CR, Mazurek MO. Video game access, parental rules, and problem behavior: a study of boys with autism spectrum disorder. Autism. 2013. doi:10.1177/1362361313482053.

16. Geier DA, Hooker BS, Kern JK, King PG, Sykes LK, Geier MR. A two-phase study evaluating the relationship between Thimerosal-containing vaccine administration and the risk for an autism spectrum disorder diagnosis in the United States. Transl Neurodegener. 2013;2(1):25. doi:10.1186/2047-9158-2-25.

17. Steffenburg S, Gillberg CL, Steffenburg U, Kyllerman M. Autism in Angelman syndrome: a population-based study. Pediatr Neurol. 1996;14(2):131-6.

18. Hartshorne TS, Grialou TL, Parker KR. Autistic-like behavior in CHARGE syndrome. Am J Med Genet Part A. 2005;133A(3): 257-61. doi:10.1002/ajmg.a.30545.

19. Howlin P, Karpf J, Turk J. Behavioural characteristics and autistic features in individuals with Cohen Syndrome. Eur Child Adolesc Psychiatry. 2005;14(2):57-64. doi:10.1007/s00787-005-0416-4.

20. Bhuiyan ZA, Klein M, Hammond P, van Haeringen A, Mannens MM, Van Berckelaer-Onnes I, et al. Genotype-phenotype correlations of 39 patients with Cornelia De Lange syndrome: the Dutch experience. J Med Genet. 2006;43(7):568-75. doi:10.1136/ jmg.2005.038240.

21. Wu JY, Kuban KC, Allred E, Shapiro F, Darras BT. Association of Duchenne muscular dystrophy with autism spectrum disorder. J Child Neurol. 2005;20(10):790-5.
22. Young HK, Barton BA, Waisbren S, Portales Dale L, Ryan MM, Webster RI, et al. Cognitive and psychological profile of males with Becker muscular dystrophy. J Child Neurol. 2008;23(2):155-62. doi:10.1177/0883073807307975.

23. Brown WT, Friedman E, Jenkins EC, Brooks J, Wisniewski K, Raguthu S, et al. Association of fragile X syndrome with autism. Lancet. 1982;1(8263): 100 .

24. Bailey DB Jr, Raspa M, Olmsted M, Holiday DB. Co-occurring conditions associated with FMR1 gene variations: findings from a national parent survey. Am J Med Genet Part A. 2008; 146A(16):2060-9.

25. Garg S, Green J, Leadbitter K, Emsley R, Lehtonen A, Evans DG, et al. Neurofibromatosis type 1 and autism spectrum disorder. Pediatrics. 2013;132(6):e1642-8. doi:10.1542/peds.2013-1868.

26. - Schaaf CP, Gonzalez-Garay ML, Xia F, Potocki L, Gripp KW, Zhang B et al. Truncating mutations of MAGEL2 cause PraderWilli phenotypes and autism. Nat Genet. 2013;45(11):1405-8. doi:10.1038/ng.2776. This study identified the single gene defect as the molecular mechanism of Prader-Willi syndrome and associated ASD.

27. Butler MG, Dasouki MJ, Zhou XP, Talebizadeh Z, Brown M, Takahashi TN, et al. Subset of individuals with autism spectrum disorders and extreme macrocephaly associated with germline PTEN tumour suppressor gene mutations. J Med Genet. 2005;42(4): 318-21.

28. • O'Roak BJ, Vives L, Fu W, Egertson JD, Stanaway IB, Phelps IG et al. Multiplex targeted sequencing identifies recurrently mutated genes in autism spectrum disorders. Science. 2012; 338(6114):1619-22. doi:10.1126/science.1227764. This study demonstrated the utility of targeted high-throughput sequencing in identifying novel genetic causes of ASD in a large cohort of sporadic cases.

29. Hagberg B, Aicardi J, Dias K, Ramos O. A progressive syndrome of autism, dementia, ataxia, and loss of purposeful hand use in girls: Rett's syndrome: report of 35 cases. Ann Neurol. 1983;14(4):471-9. doi:10.1002/ana.410140412.

30. Dykens EM, Finucane BM, Gayley C. Brief report: cognitive and behavioral profiles in persons with Smith-Magenis syndrome. J Autism Dev Disord. 1997;27(2):203-11.

31. Morrow JD, Whitman BY, Accardo PJ. Autistic disorder in Sotos syndrome: a case report. Eur J Pediatr. 1990;149(8):567-9.

32. Smalley SL, Tanguay PE, Smith M, Gutierrez G. Autism and tuberous sclerosis. J Autism Dev Disord. 1992;22(3):339-55.

33. Jaeken J, Van den Berghe G. An infantile autistic syndrome characterised by the presence of succinylpurines in body fluids. Lancet. 1984;2(8411):1058-61.

34. - Novarino G, El-Fishawy P, Kayserili H, Meguid NA, Scott EM, Schroth $\mathbf{J}$ et al. Mutations in BCKD-kinase lead to a potentially treatable form of autism with epilepsy. Science. 2012;338(6105): 394-7. doi:10.1126/science.1224631. This recent article reported a rare autosomal recessive form of autism due to an enzymatic deficiency in the amino acid metabolic pathway. This is of particular interest, because it suggests that some form of ASDs may be potentially treatable through nutritional supplementation.

35. Celestino-Soper PB, Shaw CA, Sanders SJ, Li J, Murtha MT, Ercan-Sencicek AG, et al. Use of array CGH to detect exonic copy number variants throughout the genome in autism families detects a novel deletion in TMLHE. Hum Mol Genet. 2011;20(22):4360-70. doi:10.1093/hmg/ddr363.

36. Baieli S, Pavone L, Meli C, Fiumara A, Coleman M. Autism and phenylketonuria. J Autism Dev Disord. 2003;33(2):201-4.

37. Wijburg FA, Wegrzyn G, Burton BK, Tylki-Szymanska A. Mucopolysaccharidosis type III (Sanfilippo syndrome) and misdiagnosis of idiopathic developmental delay, attention deficit/ hyperactivity disorder or autism spectrum disorder. Acta Paediatr. 2013;102(5):462-70. doi:10.1111/apa.12169. 
38. Sikora DM, Pettit-Kekel K, Penfield J, Merkens LS, Steiner RD. The near universal presence of autism spectrum disorders in children with Smith-Lemli-Opitz syndrome. Am J Med Genet Part A. 2006;140(14):1511-8. doi:10.1002/ajmg.a.31294.

39. Carter MT, Scherer SW. Autism spectrum disorder in the genetics clinic: a review. Clin Genet. 2013;83(5):399-407. doi:10.1111/ cge. 12101.

40. Marshall CR, Noor A, Vincent JB, Lionel AC, Feuk L, Skaug J, et al. Structural variation of chromosomes in autism spectrum disorder. Am J Hum Genet. 2008;82(2):477-88.

41. Moss J, Richards C, Nelson L, Oliver C. Prevalence of autism spectrum disorder symptomatology and related behavioural characteristics in individuals with Down syndrome. Autism. 2013;17(4):390-404. doi:10.1177/1362361312442790.

42. Bishop DV, Jacobs PA, Lachlan K, Wellesley D, Barnicoat A, Boyd PA, et al. Autism, language and communication in children with sex chromosome trisomies. Arch Dis Child. 2011;96(10): 954-9. doi:10.1136/adc.2009.179747.

43. Leroy C, Landais E, Briault S, David A, Tassy O, Gruchy N, et al. The 2q37-deletion syndrome: an update of the clinical spectrum including overweight, brachydactyly and behavioural features in 14 new patients. Eur J Hum Genet. 2013;21(6):602-12. doi:10. 1038/ejhg.2012.230

44. Al Ageeli E, Drunat S, Delanoe C, Perrin L, Baumann C, Capri $\mathrm{Y}$, et al. Duplication of the 15q11-q13 region: clinical and genetic a study of 30 new cases. Eur J Med Genet. 2013;57(1):5-14. doi:10.1016/j.ejmg.2013.10.008.

45. Simons Vip Consortium. Simons Variation in Individuals Project (Simons VIP): a genetics-first approach to studying autism spectrum and related neurodevelopmental disorders. Neuron. 2012;73(6):1063-7. doi:10.1016/j.neuron.2012.02.014.

46. Sebat J, Lakshmi B, Malhotra D, Troge J, Lese-Martin C, Walsh $\mathrm{T}$, et al. Strong association of de novo copy number mutations with autism. Science. 2007;316(5823):445-9.

47. Shen Y, Dies KA, Holm IA, Bridgemohan C, Sobeih MM, Caronna EB, et al. Clinical genetic testing for patients with autism spectrum disorders. Pediatrics. 2010;125(4):e727-35.

48. Miller DT, Adam MP, Aradhya S, Biesecker LG, Brothman AR, Carter NP, et al. Consensus statement: chromosomal microarray is a first-tier clinical diagnostic test for individuals with developmental disabilities or congenital anomalies. Am J Hum Genet. 2010;86(5):749-64.

49. Stobbe G, Liu Y, Wu R, Hudgings LH, Thompson O, Hisama FM. Diagnostic yield of array comparative genomic hybridization in adults with autism spectrum disorders. Genet Med. 2013; doi:10.1038/gim.2013.78.

50. Roberts JL, Hovanes K, Dasouki M, Manzardo AM, Butler MG. Chromosomal microarray analysis of consecutive individuals with autism spectrum disorders or learning disability presenting for genetic services. Gene. 2013; doi:10.1016/j.gene.2013.10. 020.

51. Vallespin E, Palomares Bralo M, Mori MA, Martin R, GarciaMinaur S, Fernandez L, et al. Customized high resolution CGHarray for clinical diagnosis reveals additional genomic imbalances in previous well-defined pathological samples. Am J Med Genet Part A. 2013;161(8):1950-60. doi:10.1002/ajmg.a.35960.

52. Battaglia A, Doccini V, Bernardini L, Novelli A, Loddo S, Capalbo A, et al. Confirmation of chromosomal microarray as a first-tier clinical diagnostic test for individuals with developmental delay, intellectual disability, autism spectrum disorders and dysmorphic features. Eur J Paediatr Neurol. 2013;17(6): 589-99. doi:10.1016/j.ejpn.2013.04.010.

53. Palmer E, Speirs H, Taylor PJ, Mullan G, Turner G, Einfeld S, et al. Changing interpretation of chromosomal microarray over time in a community cohort with intellectual disability. Am J Med Genet Part A. 2013;. doi:10.1002/ajmg.a.36279.
54. Nicholl J, Waters W, Mulley JC, Suwalski S, Brown S, Hull Y, et al. Cognitive deficit and autism spectrum disorders: prospective diagnosis by array CGH. Pathology. 2013; doi:10.1097/ PAT.0000000000000043.

55. •- Schaefer GB, Mendelsohn NJ, Professional P, Guidelines C. Clinical genetics evaluation in identifying the etiology of autism spectrum disorders: 2013 guideline revisions. Genet Med. 2013;15(5):399-407. doi:10.1038/gim.2013.32. This professional practice guideline of the American College of Medical Genetics and Genomics provides a comprehensive overview of the genetic basis of ASD and illustrated key points to consider during clinical evaluation of ASD.

56. Kumar RA, KaraMohamed S, Sudi J, Conrad DF, Brune C, Badner JA, et al. Recurrent 16p11.2 microdeletions in autism. Hum Mol Genet. 2008;17(4):628-38. doi:10.1093/hmg/ddm376.

57. Weiss LA, Shen Y, Korn JM, Arking DE, Miller DT, Fossdal R, et al. Association between microdeletion and microduplication at 16p11.2 and autism. N Engl J Med. 2008;358(7):667-75.

58. Miller DT, Shen Y, Weiss LA, Korn J, Anselm I, Bridgemohan C, et al. Microdeletion/duplication at 15q13.2q13.3 among individuals with features of autism and other neuropsychiatric disorders. J Med Genet. 2008;46(4):242-8.

59. Ben-Shachar S, Lanpher B, German JR, Qasaymeh M, Potocki L, Nagamani SC, et al. Microdeletion 15q13.3: a locus with incomplete penetrance for autism, mental retardation, and psychiatric disorders. J Med Genet. 2009;46(6):382-8.

60. Gauthier J, Champagne N, Lafreniere RG, Xiong L, Spiegelman $\mathrm{D}$, Brustein E, et al. De novo mutations in the gene encoding the synaptic scaffolding protein SHANK3 in patients ascertained for schizophrenia. Proc Natl Acad Sci USA. 2010;107(17):7863-8. doi:10.1073/pnas.0906232107.

61. Awadalla P, Gauthier J, Myers RA, Casals F, Hamdan FF, Griffing AR, et al. Direct measure of the de novo mutation rate in autism and schizophrenia cohorts. Am J Hum Genet. 2010;87(3): 316-24. doi:10.1016/j.ajhg.2010.07.019.

62. • Coulter ME, Miller DT, Harris DJ, Hawley P, Picker J, Roberts $\mathrm{AE}$ et al. Chromosomal microarray testing influences medical management. Genet Med. 2011;13(9):770-6. doi:10.1097/GIM. 0b013e31821dd54a. This recent study reported the impact of genetic tests, in particular clinical chromosomal microarray testing, on medical management.

63. Abdul-Rahman OA, Hudgins L. The diagnostic utility of a genetics evaluation in children with pervasive developmental disorders. Genet Med. 2006;8(1):50-4.

64. Magiati I, Charman T, Howlin P. A two-year prospective followup study of community-based early intensive behavioural intervention and specialist nursery provision for children with autism spectrum disorders. J Child Psychol Psychiatry. 2007;48(8): 803-12.

65. Altemeier WA, Altemeier LE. How can early, intensive training help a genetic disorder? Pediatr Ann. 2009;38(3):167-170, 172.

66. Dawson G, Burner K. Behavioral interventions in children and adolescents with autism spectrum disorder: a review of recent findings. Curr Opin Pediatr. 2011;23(6):616-20. doi:10.1097/ MOP.0b013e32834cf082.

67. Constantino J, Zhang Y, Frazier T, Abbacchi AM, Law P. Sibling recurrence and the genetic epidemiology of autism. Am J Psychiatry. 2010;167(11):1349-56.

68. Gronborg TK, Schendel DE, Parner ET. Recurrence of autism spectrum disorders in full- and half-siblings and trends over time: a population-based cohort study. JAMA Pediatr. 2013;167(10): 947-53. doi:10.1001/jamapediatrics.2013.2259.

69. Ozonoff S, Young GS, Carter A, Messinger D, Yirmiya N, Zwaigenbaum L, et al. Recurrence risk for autism spectrum disorders: a Baby Siblings Research Consortium Study. Pediatrics. 2011;128(3):e488-95. doi:10.1542/peds.2010-2825. 
70. Zufferey F, Sherr EH, Beckmann ND, Hanson E, Maillard AM, Hippolyte L, et al. A $600 \mathrm{~kb}$ deletion syndrome at 16p11.2 leads to energy imbalance and neuropsychiatric disorders. J Med Genet. 2012;49(10):660-8. doi:10.1136/jmedgenet-2012-101203.

71. Moreno-De-Luca A, Myers SM, Challman TD, Moreno-De-Luca D, Evans DW, Ledbetter DH. Developmental brain dysfunction: revival and expansion of old concepts based on new genetic evidence. Lancet Neurol. 2013;12(4):406-14. doi:10.1016/ S1474-4422(13)70011-5.

72. Chlebowski C, Robins DL, Barton ML, Fein D. Large-scale use of the modified checklist for autism in low-risk toddlers. Pediatrics. 2013;131(4):e1121-7. doi:10.1542/peds.2012-1525.

73. McGrew SG, Peters BR, Crittendon JA, Veenstra-Vanderweele J. Diagnostic yield of chromosomal microarray analysis in an autism primary care practice: which guidelines to implement? J Autism Dev Disord. 2012;42(8):1582-91. doi:10.1007/s10803011-1398-3.

74. Ascano M Jr, Mukherjee N, Bandaru P, Miller JB, Nusbaum JD, Corcoran DL, et al. FMRP targets distinct mRNA sequence elements to regulate protein expression. Nature. 2012;492(7429): 382-6. doi:10.1038/nature11737.

75. Steinberg J, Webber C. The roles of FMRP-regulated genes in autism spectrum disorder: single- and multiple-hit genetic etiologies. Am J Hum Genet. 2013;93(5):825-39. doi:10.1016/j.ajhg. 2013.09.013.

76. • O'Roak BJ, Deriziotis P, Lee C, Vives L, Schwartz JJ, Girirajan $\mathrm{S}$ et al. Exome sequencing in sporadic autism spectrum disorders identifies severe de novo mutations. Nat Genet. 2011; 43(6):585-9. doi:10.1038/ng.835. This study was the first to demonstrate the power of exome sequencing in identifying de novo mutations in ASD patients.

77. Iossifov I, Ronemus M, Levy D, Wang Z, Hakker I, Rosenbaum $\mathrm{J}$, et al. De novo gene disruptions in children on the autistic spectrum. Neuron. 2012;74(2):285-99. doi:10.1016/j.neuron. 2012.04.009.

78. Neale BM, Kou Y, Liu L, Ma'ayan A, Samocha KE, Sabo A, et al. Patterns and rates of exonic de novo mutations in autism spectrum disorders. Nature. 2012;485(7397):242-5. doi:10.1038/ nature 11011.
79. Sanders SJ, Murtha MT, Gupta AR, Murdoch JD, Raubeson MJ, Willsey AJ, et al. De novo mutations revealed by whole-exome sequencing are strongly associated with autism. Nature. 2012;485(7397):237-41. doi:10.1038/nature10945.

80. Chahrour MH, Yu TW, Lim ET, Ataman B, Coulter ME, Hill RS, et al. Whole-exome sequencing and homozygosity analysis implicate depolarization-regulated neuronal genes in autism. PLoS Genet. 2012;8(4):e1002635. doi:10.1371/journal.pgen. 1002635.

81. Yu TW, Chahrour MH, Coulter ME, Jiralerspong S, OkamuraIkeda K, Ataman B, et al. Using whole-exome sequencing to identify inherited causes of autism. Neuron. 2013;77(2):259-73. doi:10.1016/j.neuron.2012.11.002.

82. • Michaelson JJ, Shi Y, Gujral M, Zheng H, Malhotra D, Jin X et al. Whole-genome sequencing in autism identifies hot spots for de novo germline mutation. Cell. 2012;151(7):1431-42. doi:10. 1016/j.cell.2012.11.019. This was the first WGS study that revealed de novo nucleotide substitutions as a significant risk factor for ASD.

83. - Jiang YH, Yuen RK, Jin X, Wang M, Chen N, Wu X et al. Detection of Clinically Relevant Genetic Variants in Autism Spectrum Disorder by Whole-Genome Sequencing. Am J Hum Genet. 2013. doi:10.1016/j.ajhg.2013.06.012. This study demonstrated the application and yield of WGS in identifying the genetic causes of ASD.

84. Chez MG, Burton Q, Dowling T, Chang M, Khanna P, Kramer C. Memantine as adjunctive therapy in children diagnosed with autistic spectrum disorders: an observation of initial clinical response and maintenance tolerability. J Child Neurol. 2007;22(5):574-9. doi:10.1177/0883073807302611.

85. Doyle CA, McDougle CJ. Pharmacotherapy to control behavioral symptoms in children with autism. Expert Opin Pharmacother. 2012;13(11):1615-29. doi:10.1517/14656566.2012.674110.

86. Hollander E, Soorya L, Chaplin W, Anagnostou E, Taylor BP, Ferretti CJ et al. A double-blind placebo-controlled trial of fluoxetine for repetitive behaviors and global severity in adult autism spectrum disorders. Am J Psychiatry. 2012;169(3):292-9. doi:10.1176/appi.ajp.2011.10050764. 